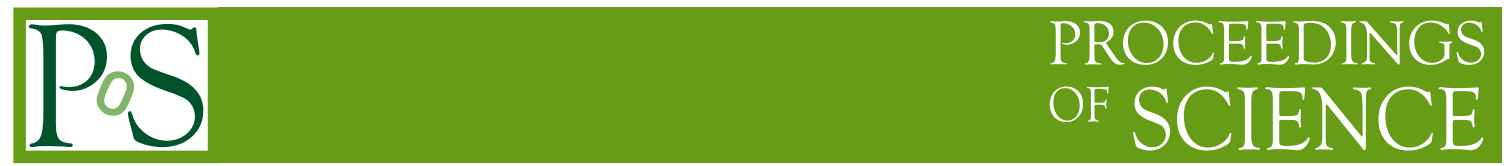

\title{
Graduate Student Days at Columbia University, 1956-1960
}

\section{Daniel Zwanziger*}

New York University

E-mail: dz2@nyu.edu

In which some personal recollections from Héctor's and my graduate student days are presented.

Quarks, Strings and the Cosmos - Héctor Rubinstein Memorial Symposium

August 09-11, 2010

AlbaNova, Stockholm, Sweden

${ }^{*}$ Speaker. 
Héctor and I were graduate students in physics together at Columbia University. I started in September, 1955. If memory serves, Héctor arrived at mid-year, Jan. 1956. This was unusual but the explanation may be quite simple: he arrived from Argentina where it was the end of summer. Héctor was part of a generation of physicists who left Argentina for essentially political reasons. This was a tragic loss for Argentina.

You all know Héctor's personality: great enthusiasm and energy for what he liked, and he was not shy about expressing dissatisfaction when called for. What did Héctor like? He arrived from Argentina with unbounded enthusiasm for the artistic, musical, philosophical and scientific accomplishments of Western culture, viewed broadly.

As an example, one day we went to the Metropolitan Museum of Art in New York City, and chanced upon a bust of Voltaire by the great portraitist sculptor Houdon, known for his life-like portraits, particularly the eyes, which seem alive. At the sight of Voltaire, the great enlightenment philosopher and Newton's standard-bearer in Cartesian France, Héctor's face lit up with the full whole-face smile of lips and eyes that you all know. I still remember the smile that lit his face at that moment more than a half-century ago. That same smile, expressive of deep satisfaction, lit his face again, after his first visit to Greece, the fountainhead of Western culture, when he described to me his visit to the acropolis.

Héctor's love and life-long enthusiasm for physics was rooted in his commitment to Western culture in its various historical and artistic manifestations, including literature, the visual arts, music, as well as science. Héctor was disappointed that New York City did not offer - in his opinion - enough performances of contemporary composers. He was particularly fond of Messien.

Another love of Héctor at that time was the great Swedish theatre and film director Ingmar Bergmann whose films, the Seventh Seal and Wild Strawberries came out in 1957. Héctor had a healthy admiration for beautiful women, and we went to see the New York première of Wild Strawberries, at which Ingrid Thulin appeared in person. Perhaps this foreshadows that Héctor would fall in love with and marry the Swedish beauty, Helen.

At that time, the Columbia physics faculty consisted of 17 physicists. By now 8 have been awarded a Nobel prize (Rabi, Kusch, T. D. Lee, Rainwater, Townes, Lederman, Steinberger, Schwartz). Mme. C. S. Wu was also on the faculty, and Weinberg and Mandelstam were in junior positions. The Columbia physics department was arguably as strong any on the planet. What characterized it uniquely, in my experience, was the close collaboration and interaction between theorists and experimentalists.

It was the universal custom for graduate students to work on a research problem suggested by a faculty advisor. Héctor, always unique and pursuing his own ideas, chose his own problem - multiple particle production - and then got Professor Robert Serber to be his supervisor. Myron Bander however has recently informed me that Héctor submitted for his $\mathrm{Ph}$. D. thesis a compendium of work that he did subsequently in Paris on the N/D method and related topics in particle physics.

Research by graduate students in physics at Columbia University was interrupted for several weeks by an epidemic of the Japanese game of go. Héctor and Myron and I were badly infected. The game appealed to Héctor's competitive instincts, and he was an intense and strong player.

Another popular wave at the time were the Italian motor scooters Vespa and Lambretta. Héctor and I had Lambrettas. The formal graduate courses at Columbia at that time ended with a one-year course in quantum mechanics taught by Professor Serber. Héctor - always the activist - learned 
that Bruno Zumino was lecturing in Quantum Field Theory downtown at New York University in evening lectures. Héctor proposed that we attend, and we weekly rode downtown on our Lambrettas from 120th to 4th street to attend Zumino's lectures. That is how I was introduced to the KällenLehmann representation. Héctor also took the initiative in asking Stanley Mandelstam to give a series of lectures in Quantum Field Theory to a group of graduate students.

Héctor's ebullient personality, his broad interests in cultural matters, and his enthusiasms and initiatives made our lives as graduate students exciting and intellectually intense. These were the qualities that marked his subsequent career in Paris, Israel and Sweden.

A photograph which I took is appended. It was taken in the summer of 1969 at the country home of Héctor and Helen in Bastad, Sweden. From the left the standing adults are Miguel Virasoro, Adonis Verganelakis, Héctor Rubinstein, Helen Rubinstein, Elizabeth Hegeman, Barbel von Gehlen. 